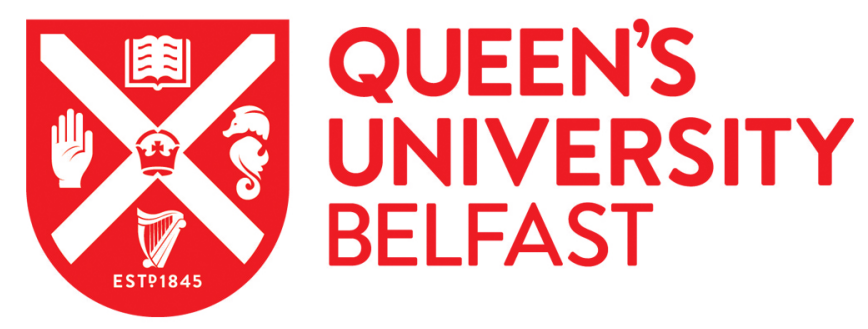

\title{
Sexism Predicts Alcohol Use and Motivations Among College Women with Stronger Alcohol Identity
}

Petzel, Z. W., \& Casad, B. J. (2019). Sexism Predicts Alcohol Use and Motivations Among College Women with Stronger Alcohol Identity. Social Cognition, 37(3), 341-354.

Published in:
Social Cognition

Document Version:

Peer reviewed version

Queen's University Belfast - Research Portal:

Link to publication record in Queen's University Belfast Research Portal

Publisher rights

(C) 2019 Guilford Press.

This work is made available online in accordance with the publisher's policies. Please refer to any applicable terms of use of the publisher.

\section{General rights}

Copyright for the publications made accessible via the Queen's University Belfast Research Portal is retained by the author(s) and / or other copyright owners and it is a condition of accessing these publications that users recognise and abide by the legal requirements associated with these rights.

Take down policy

The Research Portal is Queen's institutional repository that provides access to Queen's research output. Every effort has been made to ensure that content in the Research Portal does not infringe any person's rights, or applicable UK laws. If you discover content in the Research Portal that you believe breaches copyright or violates any law, please contact openaccess@qub.ac.uk. 
Sexism Predicts Alcohol Use and Motivations Among College Women with Stronger Alcohol Identity

Zachary W. Petzel ${ }^{1} \&$ Bettina J. Casad ${ }^{2}$

${ }^{1}$ Queen’s University Belfast, ${ }^{2}$ University of Missouri - St. Louis

\section{Author Note}

Zachary W. Petzel, School of Psychology, Queen’s University Belfast; Bettina J. Casad, Department of Psychological Sciences, University of Missouri-St. Louis.

Correspondence regarding this article should be addressed to Zachary W. Petzel, School of Psychology, Queen's University Belfast, 18-30 Malone Rd, Belfast, BT9 5BN, UK. E-mail: z.petzel@qub.ac.uk 


\begin{abstract}
Nearly half of college students engage in risky alcohol use and college women may be more likely than men to drink in excess. However, little research has examined predictors of alcohol use unique to college women. College women often experience sexism; however, whether sexism contributes to greater alcohol use is not well established. The present study assessed alcohol-related outcomes among college women, examining the interaction between sexism and alcohol identity, associations in memory between self and alcohol-related constructs. Part 1 found greater anticipation of sexism predicted higher self-reported alcohol use among women strongly identifying with alcohol. Part 2 manipulated the presence of sexist feedback and assessed automatic alcohol action tendencies. Results indicated women receiving sexist feedback strongly identifying with alcohol exhibited greater automatic tendencies toward alcohol compared to women receiving non-sexist feedback. Results suggest sexism may contribute to greater alcohol use among college women who strongly identify with alcohol.
\end{abstract}


Sexism Predicts Alcohol Use and Motivations Among College Women with Stronger Alcohol Identity

Despite prevention efforts, approximately $44 \%$ of college drinkers engage in risky alcohol use compared to only $36 \%$ of their non-student peers (Hingson $\&$ White, 2014). Further, college women may be more likely than college men to drink in excess (Hoeppner et al., 2013; Young, Morales, Esteban, Boyd, \& D’Arcy, 2005). Whereas men are more likely to be diagnosed with an alcohol use disorder (AUD), women are more likely to start abusing alcohol at earlier ages and increase their rate of alcohol consumption more rapidly (Brady \& Randall, 1999; Hernandez-Avila, Rounsaville, \& Kranzler, 2004; Zilberman, Tavares, El-Guebaly, 2004). The negative effects of alcohol use are also greatly exacerbated among women, leading to quicker atrophy of the brain, heart, and muscles (Mann et al., 2005). Despite these concerns, little research has examined social cognitive factors that may influence excess drinking specific to college women. An unexplored predictor of alcohol use among college women is negative social interactions due to experiences of stigma (i.e., belonging to a devalued social group). The present research examines whether experiencing stigma-based social rejection (i.e., sexism) predicts alcohol-related outcomes among college women.

Among women, sexism is associated with poorer academic performance (Schmader, 2002), working memory (Schmader \& Johns, 2003), and self-control capacity (Inzlicht, McKay, \& Aronson, 2006). Whereas poorer academic performance (Singleton, 2007), working memory (Khurana et al., 2013), and self-control capacity (Muraven, Collins, \& Nienhaus, 2002) are linked to greater alcohol use, sexism has not been explicitly linked to greater alcohol use among college women. Experiencing sexism is related to many negative physical and mental health outcomes (e.g., depression, anxiety, hypertension, heart disease, and stroke; Brown \& Pinel, 
2003; Hunger \& Major, 2015; Lewis, Derlega, Griffin, \& Krowinski, 2003; Major \& O'Brien, 2005; Major, Mendes, \& Dovidio, 2013; Pascoe \& Smart Richman, 2009). These negative consequences are triggered through mere expectations to experience sexism (i.e., gender stigma consciousness; Pinel, 1999) or acute sexism (Eliezer, Major, \& Mendes, 2009). However, neither anticipated or acute sexism have been linked to risky alcohol use among college women.

Women likely experience chronic stress due to anticipation of being the target of sexism (Major \& O'Brien, 2005), which may be a precursor to greater alcohol use (Ayer, Harder, Rose, \& Helzer, 2011; Beck, Thombs, Mahoney, \& Fingar, 1995; Simpson \& Arroyo, 1998). Targets of discrimination also exhibit increased risk-taking (Jamieson, Koslov, Nock, \& Mendes, 2013). Black Americans experiencing racism are likely to develop harmful, long-term alcohol abuse and report more frequent instances of alcohol-related problems (i.e., police involvement, missing work; Gibbons, Gerrard, Cleveland, Willis, \& Brody, 2004; Gibbons et al., 2007). Whereas college students typically drink for social or enhancement motives, experiences of discrimination predict unique variance in alcohol use among college students who belong to stigmatized groups (Hatzenbuehler, Corbinb, \& Fromme, 2011). However, whether sexism is similarly related to greater alcohol use among college women is understudied.

Responses to sexism are typically moderated by individual differences (Eliezer, Major, \& Mendes, 2010; Pinel, 2004), thus, it is unlikely all women would engage in alcohol use following sexism. Further, alcohol use among college students is related to alcohol-related individual differences such as alcohol identity (i.e., the strength of associations between self-related and alcohol-related concepts in memory). Revisions of the theory of planned behavior suggest highly relevant self-concepts are predictive of behaviors like alcohol use (Collins \& Carey, 2007; Conner \& Armitage 1998; Fekadu \& Kraft, 2001). Alcohol identity is an established self-concept 
known to predict alcohol consumption, cravings, and alcohol-related problems among college students (Gray, LaPlante, Bannon, Ambady, \& Shaffer, 2011; Lindgren et al., 2013). Further, alcohol identity accounts for greater variance in alcohol use compared to other alcohol-related individual differences (e.g., alcohol motivations; Lindgren et al., 2013) and consistently predicts alcohol consumption over time (Lindgren et al., 2016). Whereas research demonstrates alcohol identity's usefulness in predicting alcohol use (Gray et al., 2011), its role in predicting alcohol use among following discrimination is unknown.

\section{Current Research}

We aim to extend the literature by examining the interaction between sexism and alcohol identity in predicting alcohol use. We test these relations among college women, since they are likely to be aware of and anticipate sexism (i.e., gender stigma consciousness; Pinel, 1999) and experience sexism on college campuses (Friedman \& Leaper, 2010; Swim, Hyers, Cohen, \& Ferguson, 2001). We hypothesize (1) greater experiences of sexism and (2) stronger alcohol identity will predict greater alcohol-related outcomes. We expect these factors will interact, such that (3) college women strongly identifying with alcohol who experience sexism will exhibit greater alcohol-related outcomes compared to women who do not experience sexism.

We first tested these hypotheses using a cross-sectional study examining self-reported anticipation of sexism. The mere anticipation of discrimination, like sexism, may contribute to poor mental and physical health among stigmatized groups (Major \& O’Brien, 2005; Pascoe \& Smart Richman, 2009; Sawyer, Major, Casad, Townsend, \& Mendes, 2011). Gender stigma consciousness is the extent to which women are aware of sexism and how often they expect to experience sexism (Crocker \& Major, 1989; Pinel, 2002), and is associated with poorer academic performance (Brown \& Lee, 2005; Pinel, Warner, \& Chua, 2005), mental health (Lewis et al., 
2003), and physical health (Hunger \& Major, 2015; Lewis, Derlega, Clarke, \& Kuang, 2006). Part 1 of this study examined how mere awareness of sexism, and its interaction with alcohol identity, relates to alcohol use among college women. We then manipulated exposure to acute sexism during a follow-up lab session assessing behavioral measures of automatic alcohol tendencies, which predict drinking history and acute alcohol use (i.e., in the lab; Wiers, Eberl, Rinck, Becker, and Lindenmeyer, 2011; Wiers, Rinck, Dictus, \& Van den Wildenberg, 2009).

\section{Part 1}

\section{Method}

Participants. Participants $(N=302)$ were female undergraduate students recruited through the Psychology research subject pool at the University of Missouri - St. Louis who reported consuming at least 1 alcoholic drink in the past year $\left(M_{\text {age }}=23.14, S D_{\text {age }}=4.44\right){ }^{1}$ Ninety-five percent of participants reported drinking an alcoholic drink in the past 30 days. The sample included 56.6\% Caucasians $(n=171), 28.8 \%$ African Americans $(n=87), 4.6 \%$ Multiracial individuals $(n=14)$, and 10\% Asian Americans and Pacific Islanders, Latinas, Middle Easterners, and other racial/ethnic groups. Participants were compensated with course credit. A sensitivity power analysis indicated an approximately small to medium effect size $(\beta=$ 0.16) would provide $80 \%$ power to detect significant effects with the recruited sample.

Measures and procedure. After providing informed consent, participants completed an online survey hosted by Qualtrics (Provo, UT) that included demographic questions and filler items (e.g., campus involvement). Participants then reported gender stigma consciousness using a scale developed by Pinel (1999). Ten items $(\alpha=.83)$ were rated on a 6-point scale, ranging from 1 (Very strongly disagree) to 6 (Very strongly agree). Higher values indicated greater anticipation and awareness of sexism. Example items included, "Stereotypes about women have 
not affected me personally" (reverse coded), and, "Most men have a problem viewing women as equals." Alcohol use was assessed using items adapted from the National Institute on Alcohol Abuse and Alcoholism (NIAAA) Task Force on Recommended Alcohol Questions (NIAAA, 2003). Participants reported average number of drinking occasions (e.g., once a month) and average number of drinks consumed per occasion in the past 3 months. The number of drinking occasions was multiplied by drinks consumed per occasion to create a quantity/frequency variable with higher scores reflecting greater alcohol use (Bailey \& Bartholow, 2016; Jackson \& Sher, 2006).

Participants then completed an Implicit Association Test (IAT; Gray et al., 2011) assessing alcohol identity using Inquisit software hosted on Millisecond.com (Seattle, WA). The task was created using standard IAT procedures (Greenwald, McGhee, \& Schwartz, 1998). Categories were alcohol-related images (e.g., beer, liquor, wine, mixed drinks), water-related images, self-relevant words (e.g., "me," "my," "myself”) and other-relevant words (e.g., "their, "them," "others"), a common method to assess implicit identity (Gray et al., 2011; Greenwald \& Farnham, 2000). Congruent trials required participants to sort stimuli to either the joint category "alcohol or me" or "water or not me," while in incongruent trials, these pairings were switched to "water or me" and "alcohol or not me." Presentation of congruent and incongruent trial blocks were counterbalanced. Scores for the alcohol identity IAT were calculated using the D score algorithm, with errors requiring participants to correct their responses (i.e., $\mathrm{D}_{1}$; Greenwald, Nosek, \& Banaji, 2003). No individuals met criteria to be screened out for excessive errors or reaction times (Nosek, Greenwald, \& Banaji, 2007). The IAT had good internal consistency, $r(300)=.70, p<.001$. All measures are reported and were approved by the university's institutional review board. 


\section{Results}

Table 1 displays descriptives and correlations among study variables. The PROCESS macro for SPSS 23 (Hayes, 2012) was used to assess main effects and interactions. For 2-way interactions, gender stigma consciousness and alcohol identity were used as continuous predictor variables of alcohol use and were mean centered before computing the interaction to reduce multicollinearity and simplify interpretation (Tabachnick \& Fidel, 1996). For significant interactions, simple slopes were computed at 3 levels $(-1 S D, M,+1 S D)$ of the predictor variable. Because alcohol use was positively skewed with an overrepresentation of participants with low alcohol use $($ skew $=1.71)$, scores were normalized using a natural-log transformation to reduce skew $($ skew $=0.56)$ to allow for parametric testing.

\section{INSERT TABLE 1 HERE}

Stigma consciousness was not significantly related to natural log-transformed alcohol use, $t(298)=1.75, b=0.78,95 \% \mathrm{CI}[-0.01,0.16], S E=0.04, \beta=0.12, p=.08$, contrary to hypothesis 1 . Alcohol identity significantly predicted alcohol use, $t(298)=3.82, b=0.48,95 \%$ CI [0.04, 0.99], $S E=0.26, \beta=0.42, p<.001$, supporting hypothesis 2 . The interaction between stigma consciousness and alcohol identity was also significant in predicting use, $t(298)=2.51, b$ $=0.19,95 \% \mathrm{CI}[0.04,0.33], S E=0.08, \beta=0.38, p=.01$, supporting hypothesis $3 .{ }^{2}$ Simple effects indicated alcohol identity was positively related to alcohol use among women reporting higher levels of stigma consciousness, $t(298)=2.71, b=0.45,95 \% \mathrm{CI}[0.12,0.77], S E=0.05, p$ $=.007$. No significant relation was present among women reporting average or lower gender stigma consciousness, both $p \mathrm{~s}>.47$ (see Figure 1). 
Figure 1. Interaction between gender stigma consciousness and implicit alcohol identity predicting log-transformed alcohol use. Higher values on the y-axis indicate greater alcohol use. Higher values on the x-axis indicate greater implicit identification with alcohol. Gender stigma consciousness and implicit alcohol identity are graphed at -1 SD (lower), at the mean (average), and $+1 \mathrm{SD}$ (higher). ${ }^{* *} p<.01$

\section{Discussion}

Consistent with hypotheses, women with greater anticipation of sexism reported greater alcohol use when strongly identifying with alcohol. However, due to the cross-sectional design, these data are interpreted with caution. Notwithstanding this limitation, these results address a gap in the literature, being one of few studies demonstrating the relation between stigma consciousness and health behaviors (Hunger \& Major, 2015; Lewis et al., 2006). Limitations of this study include the use of explicit measures and using a cross-sectional design. Self-reported measures of sensitive topics, like alcohol use, may not capture actual consumption, particularly when assessing alcohol use among individuals with embarrassing, illegal, or problematic drinking (Gray et al., 2011; Greenwald, Poehlman, Uhlmann, \& Banaji, 2009). This limitation could be addressed through using automatic, behavioral measures. Further, gender stigma consciousness only assesses anticipation of sexism, not direct experiences with sexism. While these results are promising, whether sexism is related to alcohol use among college women strongly identifying with alcohol is inconclusive. Specifically, whether direct exposure to sexism promotes behavioral tendencies toward alcohol among college women is unknown.

\section{Part 2}

\section{Method}


Participants. Following completion of part 1, participants indicated their availability within the next week to complete the second portion of the study. Interested participants $(N=60)$ were female undergraduate students and were offered additional course credit through the Psychology research subject pool at the University of Missouri - St. Louis. ${ }^{1}$ No significant differences in any study variables emerged between participants who did and did not participate in part 2, all $p s>.382$. Participants were excluded for not following instructions $(n=2)$ and computer error $(n=2) .{ }^{3}$ Remaining participants $\left(N=56 ; M_{\text {age }}=24.56, S D_{\text {age }}=6.99\right)$ included 57.1\% Caucasians $(n=32), 26.8 \%$ African Americans $(n=15), 7.1 \%$ Multiracial individuals $(n$ $=4$ ), and 9\% Asian Americans and Pacific Islanders, Latinas, Middle Easterners, and other racial/ethnic groups. A sensitivity power analysis indicated an approximately medium to large effect size $(\beta=0.35)$ would provide $80 \%$ power to detect significant interaction effects with the recruited sample.

Measures and procedure. Upon arrival to the lab, participants were instructed they were 1 of 3 participants scheduled for the timeslot and all participants would be setup in individual rooms for privacy. Participants were first fitted with an electroencephalogram cap and rested for an 8-minute baseline period (data not presented here). After baseline, the participant was told 1 participant would be randomly assigned to give a speech while others would be judges, instructed to give constructive feedback to the speaker through an online chat (i.e., Google Hangouts). Participants then chose a cartoon avatar to represent them in the chat session (see Jamieson et al., 2013). All confederate avatars were male and race-matched to the participant's chosen avatar. The participant then selected a piece of paper from a container to determine their role as a speaker or judge, which unbeknownst to the participant, included only pieces of paper labeled with the speaker role. 
After being assigned to the speaker role, participants were given a prompt with a paragraph outlining a speech topic related to college issues (tuition increases or parking issues; counterbalanced) and given 1 minute to prepare a 3-minute speech. Participants were instructed they would give their speech through an online chat using a webcam on a computer and would be provided feedback by other participants through a text-based chat. The researcher then left the room and, via an intercom system, told the participant to begin their speech. Participants were randomly assigned to sexism or control conditions during the speech. In the sexism condition, participants received negative, gender specific feedback from the virtual male confederates (e.g., "Is it just me, or are women not very persuasive?", "I guess women have different views on this.”), whereas participants in the control condition received negative, gender neutral feedback (e.g., "Is it just me, or is participant 2 not very persuasive?", "I guess participant 2 has different views on this."). Each condition had 8 similar comments, which were sent at identical time intervals for all participants. The term "participant 2" was used in the control condition to provide general negative feedback and not highlight participant's gender identity. During the task, participants only viewed text feedback and were unable to see their speech video.

After the speech, participants evaluated the fairness of feedback given during their speech. Four items $(\alpha=.89)$ were rated from 1 (Strongly disagree) to 6 (Strongly agree). Example items included, "The feedback I received during my speech was fair," and, "All feedback I received during my speech was deserved.” Participants then completed an approach avoidance task (AAT) to assess automatic tendencies toward alcohol using Inquisit software (Seattle, WA) adapted from Rinck and Becker (2007). Participants were presented with rectangular images of 8 alcohol- and 8 water-related images (e.g., glasses, bottles) and instructed to sort the images based on picture orientation using a joystick. Participants completed 2 blocks 
of 40 critical trials consisting of randomly presented images of 10 alcohol beverages, 10 water beverages, in both portrait and landscape orientations. ${ }^{4}$ Instructions were counterbalanced across blocks, and order of counterbalancing was randomized across participants. For example, half of the participants were first instructed to pull the joystick toward them if an image was in landscape orientation during the first block (which would also enlarge the image presented on the screen, reflecting approach tendencies) but push the joystick away if the image was in portrait orientation (shrinking the image, reflecting avoidance tendencies; Rinck \& Becker, 2007). However, these instructions were switched in the second block. Prior to critical trials, participants were presented with gray rectangles in landscape or portrait format in 10 practice trials to become accustomed to responding and were provided with error feedback if a rectangle was incorrectly sorted. To assess automatic approach tendencies toward alcohol, averaged reaction times (in milliseconds) during alcohol-approach trials were subtracted from reaction times from alcohol-avoidance trials. Positive values indicated greater automatic tendencies toward alcohol (i.e., pull toward), while negative values indicated avoidance alcohol tendencies (i.e., push away). An identical index was computed for water-related images to be used as a covariate. Internal consistency between critical blocks suggested good reliability of the AAT, $r(54)=.80, p<.001$. Following the AAT, participants completed a Stroop task, second speech without feedback, and rested for an 8-minute recovery period (data not presented here). All measures are reported and were approved by the university's institutional review board.

\section{Results}

Table 2 displays descriptives and correlations among study variables. Independent samples $t$-test suggested women who received sexist comments reported feedback as less fair $(n$ $=28 ; M=3.08, S D=0.58)$ compared to controls $(n=28 ; \mathrm{M}=3.62, S D=0.66), t(54)=3.27, p=$ 
$.002, d=0.87 ; 95 \%$ CI $[0.21,0.88]$. The PROCESS macro for SPSS 23 (Hayes, 2012) was used to assess main effects and interactions. For 2-way interactions, condition (sexism, control) was entered as a dichotomous predictor variable, while alcohol identity was used as continuous predictor variable of automatic action tendencies toward alcohol. Automatic tendencies toward neutral drinks (i.e., water) were used as a covariate to isolate automatic tendencies toward alcoholic drinks. For significant interactions, simple slopes were computed for each condition.

\section{INSERT TABLE 2 HERE}

No significant main effect of condition was present, $t(51)=1.23, b=21.94,95 \% \mathrm{CI}[-$ $26.89,57.31], S E=17.83, \beta=0.15, p=.22$, or alcohol identity, $t(51)=0.73, b=15.21,95 \% \mathrm{CI}$ [-26.89, 57.31], $S E=20.97, \beta=0.12, p=.47$, on automatic tendencies toward alcohol, contrary to hypotheses 1 and 2. The interaction between condition and alcohol identity was significant in predicting automatic tendencies toward alcohol, $t(51)=2.24, b=68.64,95 \%$ CI $[7.05,130.24]$, $S E=30.68, \beta=0.37, p=.030$, supporting hypothesis 3. Simple effects indicated among women who received sexist feedback, stronger alcohol identity predicted greater automatic tendencies toward alcohol, $t(51)=3.81, b=83.85,95 \%$ CI [39.64, 128.07], $S E=22.02, p<.001$, while no significant relation was present among controls, $p=.48$ (see Figure 2).

\section{INSERT FIGURE 2 HERE}

Figure 2. Interaction between condition (control, sexism) and implicit alcohol identity predicting automatic alcohol action tendencies. Higher values on the $y$-axis indicate greater automatic tendencies toward alcohol. Higher values on the $\mathrm{x}$-axis indicate greater implicit identification with alcohol. Implicit alcohol identity is graphed at -1 SD (lower), at the mean (average), and +1 SD (higher). ${ }^{* * *} p<.001$ 


\section{Discussion}

These results extend findings from part 1, providing evidence for the moderating role of alcohol identity in acute experiences of sexism. No main effects of feedback condition or alcohol identity emerged, contrary to hypotheses. However, college women strongly identifying with alcohol exhibited greater action tendencies toward alcohol after experiencing sexism compared to women given general negative feedback. This action tendency toward alcohol, measured by faster reactions to pulling rather than pushing alcohol-related images, is linked to risky alcohol use (Field, Kiernan, Eastwood, \& Child, 2008; Wiers, Rinck, Dictus, \& Van den Wildenberg, 2009). These findings support past research, suggesting greater action tendencies toward alcohol are influenced by other social cognitive factors (Wiers et al., 2009). Results suggest sexism may only promote greater tendencies toward alcohol among women with stronger alcohol identity, another indicator of problematic alcohol use (Gray et al., 2011).

Limitations of part 2 include the relatively small sample which may have reduced statistical power to detect significant effects. However, responses to discrimination, such as sexism, are typically moderated by individual differences (e.g., gender stigma consciousness, social costs of confronting, gender identification; Eliezer et al., 2009; Miller \& Kaiser, 2001; Pinel, 1999). Consistent with this research, we found only college women with stronger alcohol identity exhibited greater alcohol approach tendencies after experiencing sexism. Another limitation of part 2 is the use of feedback to manipulate experiences of sexism. Although similar methods have been used to manipulate experiences of discrimination (Jamieson et al., 2012), the manipulated feedback is just one form of sexism and may not reflect the diversity of microaggressions women experience on college campuses.

\section{General Discussion}


Results suggest sexism (anticipated or acute) is related to greater alcohol-related outcomes among women strongly identifying with alcohol. The present research is one of few studies examining social cognitive factors related to alcohol use specific to college women. The current research provides novel contributions to the literature and expands previous research, suggesting highly identifying with alcohol and experiencing sexism may be linked to excessive alcohol consumption. One explanation for these findings may be increases in stress related to greater stigma consciousness (Hunger \& Major, 2015; Lewis et al., 2003; Lewis et al., 2006) and experiencing discriminatory treatment (Gibbons et al., 2004, Gibbons et al., 2007; Major \& O'Brien, 2005). Among college women, alcohol may be used to cope with sexism-related stress (Ayer et al., 2011; Beck et al., 1995; Simpson \& Arroyo, 1998), particularly among women strongly identifying with alcohol. Highly identifying with concepts, such as alcohol, is positively related to the frequency of engaging in identity-related behaviors (Conner \& Armitage, 1998). Women with stronger alcohol identity may be motivated to use alcohol to cope with sexism since alcohol use is highly relevant to their self-concept. However, this assumption is beyond the scope of the present study, as it did not assess motivations to use alcohol (Cooper, 1994). Further, sexism may reduce self-control capacity (Inzlicht et al., 2006), reducing inhibition of alcohol use. Future research should examine the role of self-control capacity following sexism and drinking motives as potential factors for greater alcohol-related outcomes among women.

The nature of the relations among sexism, alcohol identity, and related outcomes could be tested longitudinally to determine directionality between these constructs. For example, excessive drinking among women is stigmatizing and may put college women at greater risk for experiencing sexism, increasing anticipation of sexism (Nolen-Hoeksema, 2004). While experiences of sexism may be related to riskier health behaviors (Hunger \& Major, 2015; Pascoe 
\& Smart Richman, 2009; Schmader et al., 2015), this is the one of few studies to link sexism to greater alcohol-related outcomes. Other factors may play a role in excessive drinking among college women and should be examined in future research (e.g., shifting gender roles; Young et al., 2005). Notwithstanding these limitations, findings provide important implications and directions for future research concerning sexism and alcohol use. While research has established the negative effects of discrimination on alcohol use among racial and sexual minorities (Baiocco, D'Alessio, \& Laghi, 2010; Gibbons et al., 2007; Miller, Pedersen, \& Marshall, 2017), the current research demonstrates sexism is related to greater alcohol-related outcomes among college women strongly identifying with alcohol. 
References

Ayer, L. A., Harder, V. S., Rose, G. L., \& Helzer, J. E. (2011). Drinking and stress: An examination of sex and stressor differences using IVR-based daily data. Drug and Alcohol Dependence, 115(3), 205-212.

Bailey, K. \& Bartholow, B. D. (2016). Alcohol words elicit reactive cognitive control in lowsensitivity drinkers. Psychophysiology, 53(11), 1751-1759.

Baiocco, R., D'Alessio, M., \& Laghi, F. (2010). Binge drinking among gay, and lesbian youths: The role of internalized sexual stigma, self-disclosure, and individuals' sense of connectedness to the gay community. Addictive Behaviors, 35(10), 896-899.

Beck, K. H., Thombs, D. L., Mahoney, C. A., \& Fingar, K. M. (1995). Social context and sensation seeking: Gender differences in college student drinking motivations. International Journal of the Addictions, 30(9), 1101-1115.

Brady, K. T. \& Randall, C. L. (1999). Gender differences in substance use disorders. Psychiatric Clinics of North America, 22(2), 241-252.

Brown, R. P. \& Lee, M. N. (2005). Stigma consciousness and the race gap in college academic achievement. Self and Identity, 4(2), 149-157.

Brown, R. P. \& Pinel, E. C. (2003). Stigma on my mind: Individual differences in the experience of stereotype threat. Journal of Experimental Social Psychology, 39(6), 626-633.

Casad, B. J. \& Petzel, Z. W. (2018). Heart rate variability moderates challenge and threat reactivity to sexism among women in STEM. Social Psychology, 49(4), 191-204.

Casad, B. J., Petzel, Z. W., \& Ingalls, E. A. (2018). A model of threatening academic environments predicts women STEM majors' self-esteem and engagement in STEM. Sex Roles. (in press). 
Collins, S. E. \& Carey, K. B. (2007). The theory of planned behavior as a model of heavy episodic drinking among college students. Psychology of Addictive Behaviors, 21(4), 498-507.

Conner, M. \& Armitage, C. J. (1998). Extending the theory of planned behavior: A review and avenues for further research. Journal of Applied Social Psychology, 28(15), 1429-1464.

Cooper, M. L. (1994). Motivations for alcohol use among adolescents: Development and validation of a four-factor model. Psychological Assessment, 6(2), 117-128.

Crocker, J. \& Major, B. (1989). Social stigma and self-esteem: The self-protective properties of stigma. Psychological Review, 96(4), 608-630.

Eliezer, D., Major, B., \& Mendes, W. B. (2010). The costs of caring: Gender identification increases threat following exposure to sexism. Journal of Experimental Social Psychology, 46(1), 159-165.

Fekadu, Z. \& Kraft, P. (2001). Self-identity in planned behavior perspective: Past behavior and its moderating effects on self-identity-intention relations. Social Behavior and Personality: An International Journal, 29(7), 671-685.

Field, M., Kiernan, A., Eastwood, B., \& Child, R. (2008). Rapid approach responses to alcohol cues in heavy drinkers. Journal of Behavior Therapy and Experimental Psychiatry, 39(3), 209-218.

Friedman, C. \& Leaper, C. (2010). Sexual-minority college women's experiences with discrimination: Relations with identity and collective action. Psychology of Women Quarterly, 34(2), 152-164. 
Gibbons, F. X., Gerrard, M., Cleveland, M. J., Wills, T. A., \& Brody, G. (2004). Perceived discrimination and substance use in African American parents and their children: A panel study. Journal of Personality and Social Psychology, 86(4), 517.

Gibbons, F. X., Yeh, H. C., Gerrard, M., Cleveland, M. J., Cutrona, C., Simons, R. L., \& Brody, G. H. (2007). Early experience with racial discrimination and conduct disorder as predictors of subsequent drug use: A critical period hypothesis. Drug and Alcohol Dependence, $88, \mathrm{~S} 27-\mathrm{S} 37$.

Gray, H. M., LaPlante, D. A., Bannon, B. L., Ambady, N., \& Shaffer, H. J. (2011). Development and validation of the alcohol identity implicit associations test (AI-IAT). Addictive Behaviors, 36(9), 919-926.

Greenwald, A. G. \& Farnham, S. D. (2000). Using the implicit association test to measure selfesteem and self-concept. Journal of Personality and Social Psychology, 79(6), 10221038.

Greenwald, A. G., McGhee, D. E., \& Schwartz, J. L. (1998). Measuring individual differences in implicit cognition: the implicit association test. Journal of Personality and Social Psychology, 74(6), 1464-1480.

Greenwald, A. G., Nosek, B. A., \& Banaji, M. R. (2003). Understanding and using the implicit association test: I. An improved scoring algorithm. Journal of Personality and Social Psychology, 85(2), 197-216.

Greenwald, A. G., Poehlman, T. A., Uhlmann, E. L., \& Banaji, M. R. (2009). Understanding and using the Implicit Association Test: III. Meta-analysis of predictive validity. Journal of Personality and Social Psychology, 97(1), 17-41. 
Hatzenbuehler, M. L., Corbin, W. R., \& Fromme, K. (2011). Discrimination and alcohol-related problems among college students: A prospective examination of mediating effects. Drug and Alcohol Dependence, 115(3), 213-220.

Hayes, A. F. (2012). PROCESS: A versatile computational tool for observed variable mediation, moderation, and conditional process modeling. [White paper]. Retrieved from http://www.afhayes.com/public/process2012.pdf

Hernandez-Avila, C. A., Rounsaville, B. J., \& Kranzler, H. R. (2004). Opioid-, cannabis-and alcohol-dependent women show more rapid progression to substance abuse treatment. Drug and Alcohol Dependence, 74(3), 265-272.

Hingson, R., \& White, A. (2014). New research findings since the 2007 Surgeon General's Call to Action to Prevent and Reduce Underage Drinking: A review. Journal of Studies on Alcohol and Drugs, 75(1), 158-169.

Hoeppner, B. B., Paskausky, A. L., Jackson, K. M., \& Barnett, N. P. (2013). Sex differences in college student adherence to NIAAA drinking guidelines. Alcoholism: Clinical and Experimental Research, 37(10), 1779-1786.

Hunger, J. M., \& Major, B. (2015). Weight stigma mediates the association between BMI and self-reported health. Health Psychology, 34(2), 172-175.

Inzlicht, M. \& Schmeichel, B. J. (2012). What is ego depletion? Toward a mechanistic revision of the resource model of self-control. Perspectives on Psychological Science, 7(5), 450463.

Inzlicht, M., McKay, L., \& Aronson, J. (2006). Stigma as ego depletion: How being the target of prejudice affects self-control. Psychological Science, 17(3), 262-269. 
Jackson, K. M. \& Sher, K. J. (2006). Comparison of longitudinal phenotypes based on number and timing of assessments: A systematic comparison of trajectory approaches II. Psychology of Addictive Behaviors, 20(4), 373-384.

Jamieson, J. P., Koslov, K., Nock, M. K., \& Mendes, W. B. (2013). Experiencing discrimination increases risk taking. Psychological Science, 24(2), 131-139.

Khurana, A., Romer, D., Betancourt, L. M., Brodsky, N. L., Giannetta, J. M., \& Hurt, H. (2013). Working memory ability predicts trajectories of early alcohol use in adolescents: the mediational role of impulsivity. Addiction, 108(3), 506-515.

Lewis, R. J., Derlega, V. J., Clarke, E. G., \& Kuang, J. C. (2006). Stigma consciousness, social constraints, and lesbian well-being. Journal of Counseling Psychology, 53(1), 48-56.

Lewis, R. J., Derlega, V. J., Griffin, J. L., \& Krowinski, A. C. (2003). Stressors for gay men and lesbians: Life stress, gay-related stress, stigma consciousness, and depressive symptoms. Journal of Social and Clinical Psychology, 22(6), 716-729.

Lindgren, K. P., Neighbors, C., Teachman, B. A., Baldwin, S. A., Norris, J., Kaysen, D., ... \& Wiers, R. W. (2016). Implicit alcohol associations, especially drinking identity, predict drinking over time. Health Psychology, 35(8), 908-918.

Lindgren, K. P., Neighbors, C., Teachman, B. A., Wiers, R. W., Westgate, E., \& Greenwald, A. G. (2013). I drink therefore I am: Validating alcohol-related implicit association tests. Psychology of Addictive Behaviors, 27(1), 1-13.

Major, B., \& O'Brien, L. T. (2005). The social psychology of stigma. Annual Review of Psychology, 56, 393-421.

Major, B., Mendes, W. B., \& Dovidio, J. F. (2013). Intergroup relations and health disparities: A social psychological perspective. Health Psychology, 32(5), 514-524. 
Mann, K., Ackermann, K., Croissant, B., Mundle, G., Nakovics, H., \& Diehl, A. (2005). Neuroimaging of gender differences in alcohol dependence: are women more vulnerable? Alcoholism: Clinical and Experimental Research, 29(5), 896-901.

Miller, C. T. \& Kaiser, C. R. (2001). A theoretical perspective on coping with stigma. Journal of Social Issues, 57(1), 73-92.

Miller, S. M., Pedersen, E. R., \& Marshall, G. N. (2017). Combat experience and problem drinking in veterans: Exploring the roles of PTSD, coping motives, and perceived stigma. Addictive Behaviors, 66, 90-95.

Muraven, M., Collins, R. L., \& Neinhaus, K. (2002). Self-control and alcohol restraint: An initial application of the self-control strength model. Psychology of Addictive Behaviors, 16(2), 113-120.

Nolen-Hoeksema, S. (2004). Gender differences in risk factors and consequences for alcohol use and problems. Clinical Psychology Review, 24(8), 981-1010.

Pascoe, E. A., \& Smart Richman, L. (2009). Perceived discrimination and health: A metaanalytic review. Psychological Bulletin, 135(4), 531-554.

Pinel, E. C. (1999). Stigma consciousness: The psychological legacy of social stereotypes. Journal of Personality and Social Psychology, 76(1), 114-128.

Pinel, E. C. (2002). Stigma consciousness in intergroup contexts: The power of conviction. Journal of Experimental Social Psychology, 38(2), 178-185.

Pinel, E. C. (2004). You're just saying that because I'm a woman: Stigma consciousness and attributions to discrimination. Self and Identity, 3(1), 39-51. 
Pinel, E. C., Warner, L. R., \& Chua, P. P. (2005). Getting there is only half the battle: Stigma consciousness and maintaining diversity in higher education. Journal of Social Issues, 61(3), 481-506.

Rinck, M. \& Becker, E. S. (2007). Approach and avoidance in fear of spiders. Journal of Behavior Therapy and Experimental Psychiatry, 38(2), 105-120.

Sawyer, P. J., Major, B., Casad, B. J., Townsend, S. S., \& Mendes, W. B. (2012). Discrimination and the stress response: Psychological and physiological consequences of anticipating prejudice in interethnic interactions. American Journal of Public Health, 102(5), 1020 1026 .

Schmader, T. (2002). Gender identification moderates stereotype threat effects on women's math performance. Journal of Experimental Social Psychology, 38(2), 194-201.

Schmader, T., \& Johns, M. (2003). Converging evidence that stereotype threat reduces working memory capacity. Journal of personality and social psychology, 85(3), 440-452.

Schmader, T., Hall, W., \& Croft, A. (2015). Stereotype threat in intergroup relations. APA Handbook of Personality and Social Psychology, 2, 447-471.

Schmeichel, B. J., Harmon-Jones, C., \& Harmon-Jones, E. (2010). Exercising self-control increases approach motivation. Journal of Personality and Social Psychology, 99(1), $162-173$

Simpson, T. L., \& Arroyo, J. A. (1998). Coping patterns associated with alcohol-related negative consequences among college women. Journal of Social and Clinical Psychology, 17(2), $150-166$

Singleton, R. A. (2007). Collegiate alcohol consumption and academic performance. Journal of Studies on Alcohol and Drugs, 68(4), 548-555. 
Swim, J. K., Hyers, L. L., Cohen, L. L., \& Ferguson, M. J. (2001). Everyday sexism: Evidence for its incidence, nature, and psychological impact from three daily diary studies. Journal of Social Issues, 57(1), 31-53.

Tabachnick, B. G., \& Fidell, L. S. (1996). Using multivariate statistics (3rd ed.). New York, NY: Harper Collins.

Wiers, R. W., Eberl, C., Rinck, M., Becker, E. S., \& Lindenmeyer, J. (2011). Retraining automatic action tendencies changes alcoholic patients' approach bias for alcohol and improves treatment outcome. Psychological Science, 22(4), 490-497.

Wiers, R. W., Rinck, M., Dictus, M., \& Van den Wildenberg, E. (2009). Relatively strong automatic appetitive action-tendencies in male carriers of the OPRM1 G-allele. Genes, Brain and Behavior, 8(1), 101-106.

Young, A. M., Morales, M., McCabe, S. E., Boyd, C. J., \& D'Arcy, H. (2005). Drinking like a guy: Frequent binge drinking among undergraduate women. Substance Use \& Misuse, 40(2), 241-267.

Zilberman, M., Tavares, H., \& El-Guebaly, N. (2004). Gender similarities and differences: The prevalence and course of alcohol and other substance-related disorders. Journal of Addictive Diseases, 22(4), 61-74. 


\section{Footnotes}

1. Sample sizes were determined a priori based on research conducted using similar designs which had sufficient power to detect medium effect sizes (see Casad \& Petzel, 2018; Casad, Petzel, \& Ingalls, 2018) and analyses were conducted after data collection was completed.

2. Subsequent analyses of the natural log-transformed variables used to create the quantity/frequency index revealed a significant interaction between gender stigma consciousness and alcohol identity predicting number of drinks consumed per occasion, $t(298)=3.32, b=0.13,95 \%$ CI $[0.05,0.20], S E=0.04, \beta=0.50, p=.001$. However, the interaction between gender stigma consciousness and alcohol identity did not significantly predict number of drinking occasions, $t(298)=1.43, b=0.06,95 \%$ CI [-0.02, 0.14], $S E=$ $0.04, \beta=0.22, p=.16$.

3. Three participants were excluded from the sexism condition and 1 participant was excluded from the control condition. Excluded participants did not differ on any study variables, all $p \mathrm{~s}$ $>.64$

4. Although Rinck and Becker (2007) utilized 80 trials per block, 40 trials per block were used in this procedure to reduce participant fatigue and shorten the length of the experimental session. 